\title{
Programme on Integrated Scientific Project Management for Women Scientists/Technologists
}

\author{
at \\ Centre for Organization Development (COD), Hyderabad \\ January 07-11, 2019 \\ Sponsored by \\ The Department of Science and Technology (DST) \\ Government of India
}

The Department of Science and Technology (DST), Government of India has authorized the Centre for Organization Development (COD) to conduct a residential Programme on Integrated Scientific Project Management for Women Scientists/Technologists during January 07-11, 2019 at its campus in Hyderabad.

The Programme aims to

1) Acquaint participants with conceptual inputs on Effective Scientific Project Management.

2) Provide exposure to participants to Tools and Techniques on Integrated Project Management.

Eligibility: Minimum 5 years of experience in Government; Academicians/Professors from Universities/Colleges should have PhD/M.Tech degree and should be involved in R\&D activities; Maximum age limit 58 years; Periodicity of training programmes: Once in a block of 2 years (starting from 2013-14); All nominations have to be from the Government sector.

Venue and Date: The Programme will be held at the Centre for Organization Development (COD), Madhapur, Hyderabad during Monday, January 7 (0930 hrs) to Friday, January 11, 2019 (1715 hrs)

The Programme is fully sponsored and funded by DST, Gol. The sponsoring organizations and participants NEED NOT pay any fee or expenses for boarding \& lodging. However, the sponsoring organizations need to bear only the travel expenses to \& fro Hyderabad of their nominees.

The participants will receive a Certificate of Participation and will become members of COD Alumni Association on conclusion of the Programme.

Last date for receiving nominations: December 19, 2018.

As per the instructions of the DST, only 25 nominations will be accepted for the programme. In view of this, organizations are invited to nominate a couple of Women Scientists/Technologists to the above programme at the earliest.

For more details and to download the nomination form, please visit:

https://codhyd.org/executive-developments/integrated-scientific-project-management -for-women-scientists-technologists/ 